\title{
Experimental evidence for crustal control over seismic fault segmentation
}

Lefevre $^{1 *}$ M., Souloumiac ${ }^{2}$ P., Cubas $^{3}$ N., Klinger $^{1 *} Y$.

(1) Université de Paris, Institut de physique du globe de Paris, CNRS, F-75005 Paris, France

(2) CY Cergy Paris Université, GEC, F-95000 Cergy, France

(3) Sorbonne Université, ISTEP, F-75005 Paris, France

marthe.lefevre1@gmail.com; klinger@ipgp.fr

\section{Supplementary materials}

Table of content

Experimental set-up 2

Model validation 3

Materials properties $\quad 6$

$\begin{array}{ll}\text { Experiment results } & 11\end{array}$

$\begin{array}{ll}\text { Seismogenic thickness } & 18\end{array}$

These supplementary materials consist only in technical descriptions and each part can be read independently of the others. 


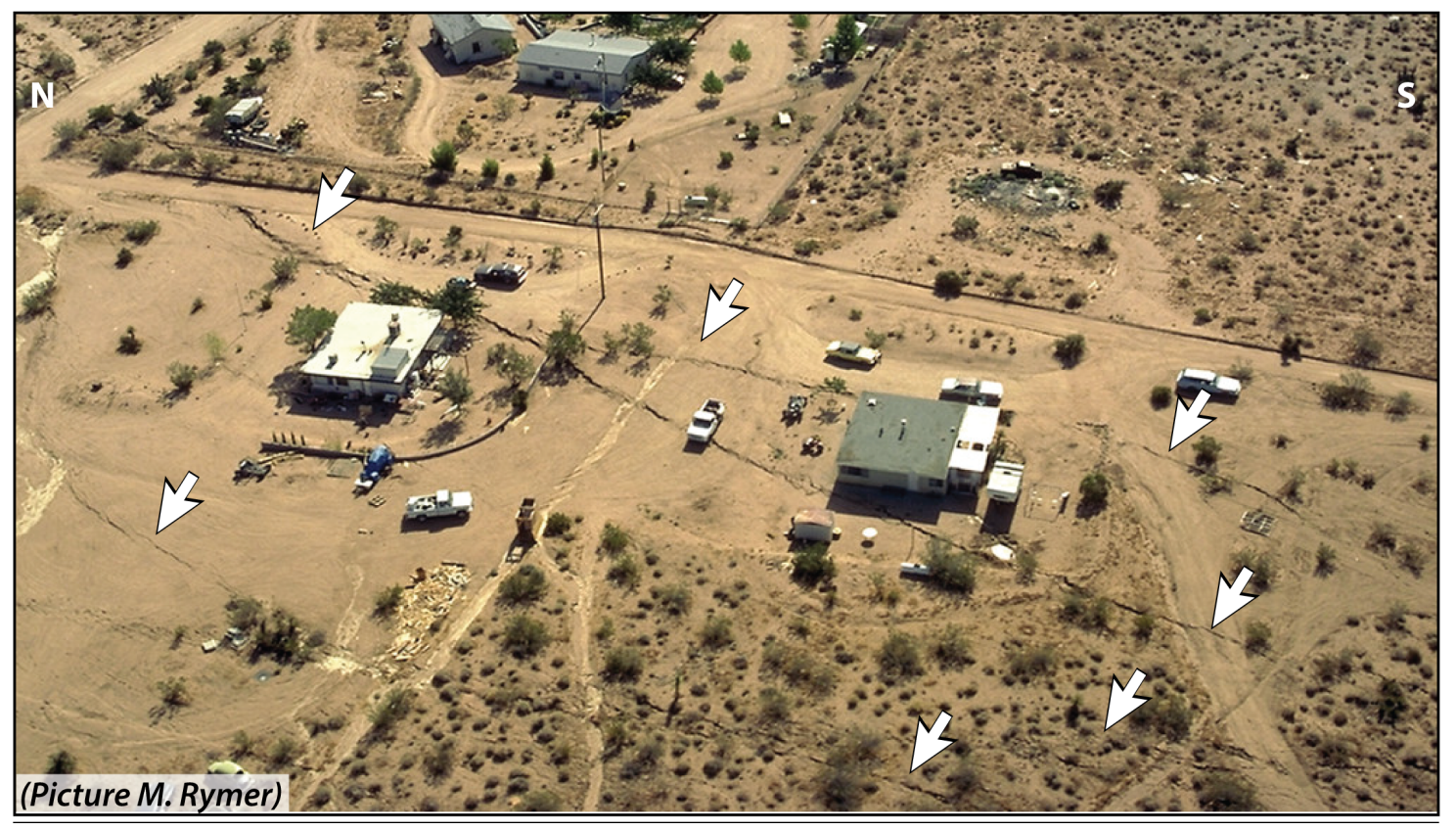

Figure S1: Aerial Picture of the Landers surface rupture along the Johnson Valley Fault (location on Fig. 1), in a small relay where the rupture presents a high degree of complexities.

\section{Experimental set-up:}

We built a strike-slip box with two adjoining PVC baseplates simulating a vertical basement fault. One plate is fixed, the second can be pushed forward with a leading screw to simulate a sinistral strike-slip fault. The box is rectangular $(120 \mathrm{~cm} * 80 \mathrm{~cm})$ and experiments can be run with or without sidewalls of adjustable size to fit the cover thickness (in that case, the sandbox size is reduced to $120 * 64 \mathrm{~cm}$ ) (Fig. 1.c, S2).

The sand pack consists of a unique flat layer, with thickness varying from 20 to $60 \mathrm{~mm}$. When possible the sandpack was sieved with the sedimentation device of Maillot 2012 to optimize the sandpack homogeneity and the experimental reproducibility (Krantz, 1991; Panien et al., 2006; Cubas et al., 2010; Maillot, 2013). The sifted sand is the reference material of our experiments (Sand 1). 


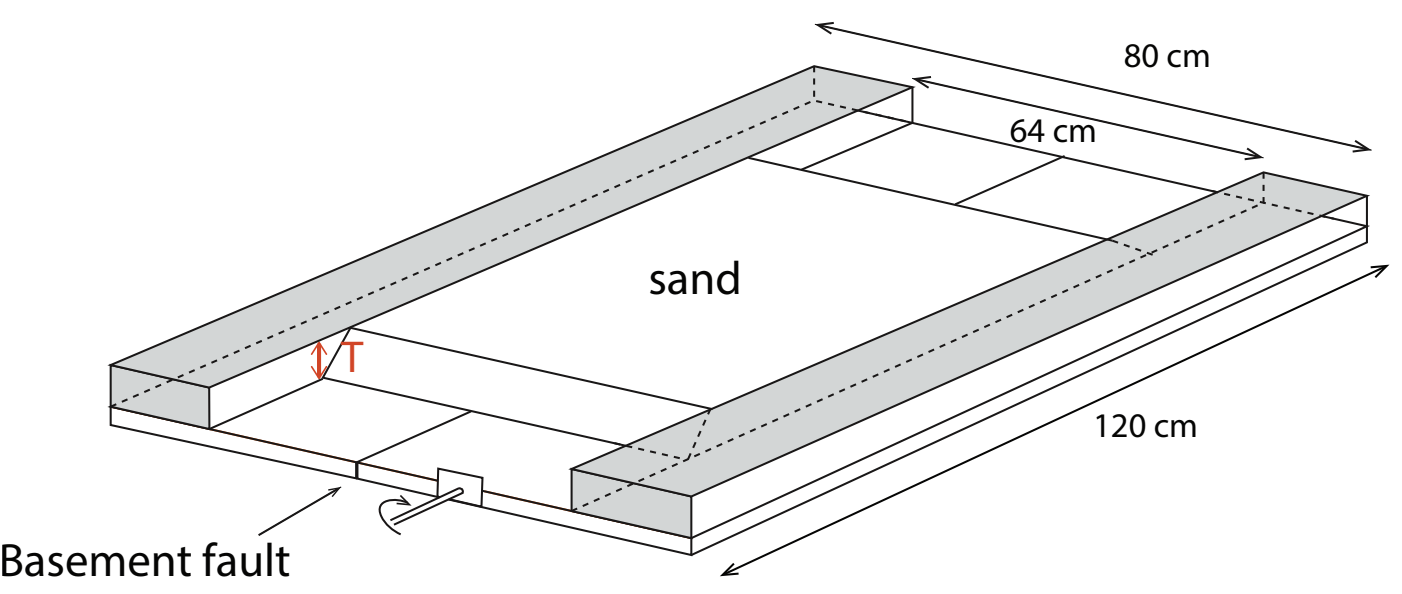

Figure S2: Oblique view of the experimental set-up, the right basal plate is pushed forward thanks to a lead screw.

A camera placed at the vertical of the box records the deformation every $0.5 \mathrm{~mm}$ of basal displacement to generate orthophotographies of the sandbox surface. The pictures resolution is of the order of the grain size, allowing for a good record of the surface structures. The analysis is based on orthophoto analysis, taken after $11-12 \mathrm{~mm}$ of displacement of the basal plate, i.e. when a series of en échelon riedels clearly appears at the surface. To assess how the shear is accommodated by the different structures during the formation of the strike-slip fault, we analysed the incremental displacement field computed from optical images correlation with the Micmac software of the IGN (Rosu et al., 2015).

We performed experiments with seven different thicknesses $(2,2.5,3,3.5,4,5 \mathrm{~cm} \pm 0.1$ $0.2 \mathrm{~cm}$ for each), which corresponds to a representative sample of the range of values for which our experimental setup remains valid. Edge effects are no longer negligible for thicker experiments in our sandbox (Fig. S3) and shear structures did not form in thinner sandpack (Fig. S4; see section of model validation for details). To obtain satisfactory statistical results, for each thickness, we performed between one and five experiments with each sand, yielding a total of 52 experiments.

\section{Model validation:}

\section{Verification of edge effect}

We noticed that high sand thicknesses led to larger standard deviations. As the deformed zone is also larger, despite of the relatively large size of the box it might have edge effects (Souloumiac et al., 2012). To validate our set-up, we investigated the effect of the box width on the inter-Riedel distance, and compared the box width/sand pack thickness ratio (box width/T) to the inter-Riedel distance/sand pack thickness ratio (S/T) in several experiments (Fig. S3). A threshold appeared. Below 16, the S/T-ratio varies a lot whereas above 16 this parameter is relatively constant. This observation 
indicates that the box width can influence the deformation. To avoid edge effects, we thus systematically worked with box dimensions above the previously defined threshold ratio.

To enlarge the box, we also made experiments without edges. The similarity of the two data sets, with and without edges, has been validated by a $\chi^{2}$ test. In the following, these results will thus be merged in a single data set for the sedimented CV32 sand.

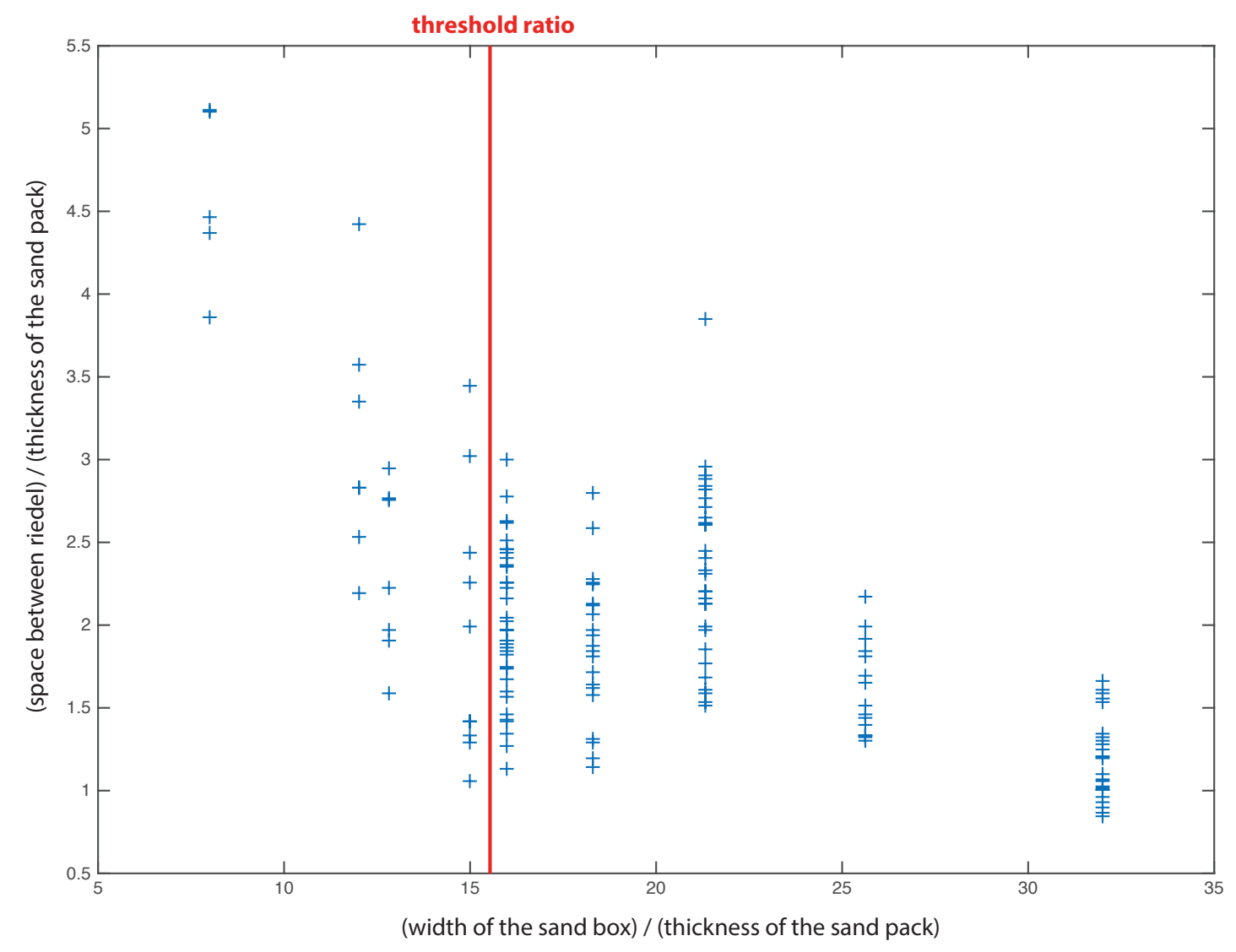

Figure S3: distribution of the S/T ratio as a function of the box width/T ratio. For narrow experiments the $\mathrm{S} / \mathrm{T}$ ratio depends on the width of the box but seems to be relatively independent for the largest experiments.

\section{Minimal thickness of the experiments}

The scaling laws derived from our experiments are expected to hold only over a certain range of sand thickness. Indeed, the sand, due to its granular nature, does not constitute a continuous medium for very thin pack, thus a minimal thickness, which depends on the grain size of the sand, is necessary to develop the 3D helicoidal shape of Riedel shears. During our experiment, no Riedel shears were visible for sand thicknesses lower than $1.5 \mathrm{~cm}$. For these low thickness experiments, a continuous fault directly appeared at the surface. Moreover, in the case of the sand 1, the deformation is confined to a central dilated zone, whose width increases linearly with the sand pack thickness (Fig. S4). The linear relation predicts that the dilated zone vanishes for thicknesses lower than $1.7 \mathrm{~cm}$, which supports the existence of a minimal thickness to form Riedel shears. 


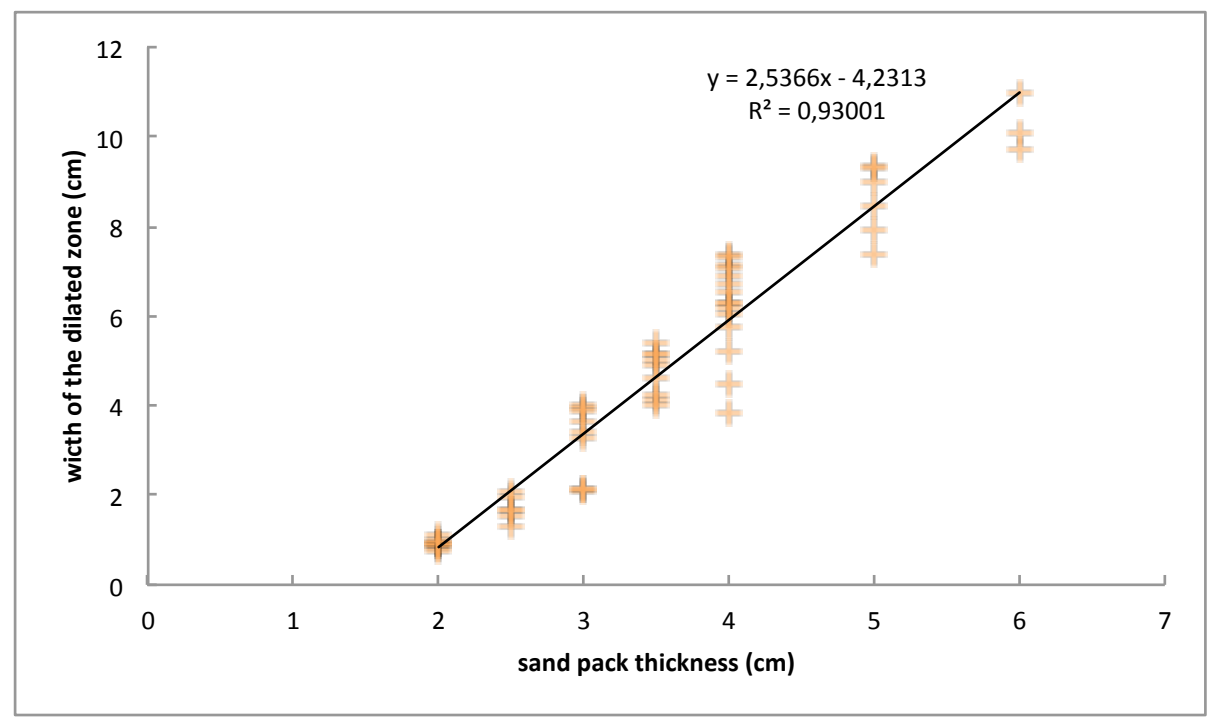

Figure S4: Evolution of the size of the central dilated zone with the thickness of the sand pack, for the sand 1.

\section{Verification of the independence of the Riedels}

To validate our model and quantitatively test the influence of the material properties on the fault geometry we need repeated experiments. As on each experiment several Riedels are visible, to limit the number of necessary experiments we need to determine whether a Riedel on the surface is an independent observable or not. We thus compared the distribution of the inter-Riedel distance (S) and the length of Riedels (L) within individual experiments to their distribution in the whole data set (Cubas et al., 2010). To compare all the experiments together, we studied the statistical distribution of the interRiedel distance/sand pack thickness ratio (S/T) (Table S1). We found consistent average values and individual standard deviations varying in the same range as the standard deviation of the whole data set, for every set-up (Table S1). Moreover, the standard deviation of the average values is substantially smaller than that of the whole corresponding set of measurements confirming the statistical convergence of the average values of each experiment. We thus consider each measurement as an independent observable. 


\begin{tabular}{|c|c|c|c|c|c|}
\hline & sedimented CV32 & poured CV32 & poured Ga39 & $\begin{array}{c}\text { sedimented CV32 } \\
\text { on Alkor-foil }\end{array}$ & $\begin{array}{l}\text { sedimented CV32 } \\
\text { on sand-paper }\end{array}$ \\
\hline $\begin{array}{l}\text { Range of the mean ratio per } \\
\text { experiment }\end{array}$ & $1.1-2.47$ & $1.07-1.34$ & $1.22-1.55$ & $1.96-2.36$ & $2.3-3.2$ \\
\hline $\begin{array}{l}\text { Mean ratio on the whole } \\
\text { data set }\end{array}$ & 1,83 & 1,18 & 1,37 & 2,18 & 2.75 \\
\hline $\begin{array}{l}\text { Range of the standard } \\
\text { deviation per experiment }\end{array}$ & $0.24-0.84$ & $0.24-0.49$ & $0.33-0.68$ & $0.58-1.06$ & $0.44-0.96$ \\
\hline $\begin{array}{l}\text { Standard deviation of the } \\
\text { mean ratio per experiment }\end{array}$ & 0.44 & 0.12 & 0.14 & 0.18 & 0.4 \\
\hline $\begin{array}{l}\text { Standard deviation on the } \\
\text { whole data set }\end{array}$ & 0.62 & 0.36 & 0.51 & 0.82 & 0.76 \\
\hline
\end{tabular}

Table S1: Average values of the inter-Riedel distance and standard deviation for all the experiments

\section{Materials properties:}

We used three different Fontainebleau Aeolian sands made of more than 98\% of quartz and known as good analogues for the brittle crust (Klinkmüller et al., 2016). Sand CV32, is a coarse poorly sorted sand with a median grain size of $250 \mu \mathrm{m}$ and a density of 1711 $\pm 7 \mathrm{~kg} / \mathrm{m} 3$ (Cubas et al., 2010; Maillot, 2013). Sand Ga39, is a fine well sorted sand with a median grain size of $90 \mu \mathrm{m}$ and a density of $1543 \pm 20 \mathrm{~kg} / \mathrm{m} 3$ (Maillot, 2013). Sand $\mathrm{C} 400$, is a very fine Fontainebleau sand with a median grain size of $13 \mu \mathrm{m}$.

This last sand is particularly fine, but we employ it only to add some cohesion in the CV32. The material resulting from the mixture of the CV32 (90\%) and the C400 (10\%) has a granulometry dominated by the one of the CV32 and is thus considered as a sand.

\section{Internal friction}

To obtain different internal frictions, we used two different sands, CV32 and Ga39. As the deposition method can greatly impact the frictional properties of granular materials (Krantz, 1991; Panien et al., 2006; Maillot, 2013), to increase the range of tested internal frictions, we also used different pouring methods: (1) sedimented with a sand distributor used to achieve a uniform sand density and a high internal friction or (2) deposed by sprinkling and scraping the sand pack for a lower friction. The highest one corresponds to the sedimented CV32, named in the manuscript Sand 1, with an 申int $=43.7^{\circ}$, the poured CV32, named Sand 3, has the lowest value, $\phi i n t=33.4^{\circ}$ (both 
values come from Maillot, 2013). We can notice that Sand 1 has a particularly high internal friction, which is due to its density. Indeed using a sand distributor to deposit the sand leads to an increase of its density (Maillot, 2013), which is particularly true for Sand 1 because it has a relatively wide range of grain size, allowing for a highly compact arrangement of the grains during the sedimentation. The compaction combined with the unsorted characteristic of its granulometry make this sand especially difficult to deform and therefore increase its internal friction and give him weakening and dilating properties.

The internal frictions of poured Ga39, named Sand 2, and of a mixture of CV32 and C400, Sand 4, were measured with a Casagrande shear device (box $6 \times 6 \mathrm{~cm}^{2}$, made by "Controls", catalogue no. 31-WF25420). The box is filled, and then scraped in order to have a planar surface. Various weights were added to the surface of the packs covered with a rigid metal piece, to obtain stresses normal to the future shear band, at 2.7, 4.7, $6.8,28.5,69.5$ and $136.5 \mathrm{kPa}$. The lower part of the box is pushed forward by a motor with a constant speed of $0.35 \mathrm{~mm} / \mathrm{s}$ creating a shear in the sand, which is measured with a dynamometric ring (Fig. S5.a). The vertical displacement of the sand pack surface is also recorded during the experiment (Fig. S5.b). The shear stress increases gradually during the first $4 \mathrm{~mm}$ of displacement before reaching a stable value (Fig. S5), the vertical displacement of the pack surface decreases slightly at the beginning before reaching a low stable value. When looking at the evolution of the shear stress with the slip, we con notice that the two sands harden continuously and do not present clear peaks leading to a difficulty in determining the difference between the static and dynamic frictions, nevertheless such behavior is not unusual, Maillot 2013 observe the same distribution for Sand 3. We use the same technique as in Maillot 2013 to determine the values of static and dynamic frictions.

The maximum value of shear stress is used to determine the static friction and the average value of the plateau yields to the dynamic friction, by linear regression for different normal constraints (Fig. S5). For Sand 2, the dynamic and static friction coefficients are close with values respectively of $34.6^{\circ}$ and $35.6^{\circ}$. For Sand 4 , we obtained lower values respectively of $20.7^{\circ}$ and $22.1^{\circ}$ (Table S2).

Both poured sands have a slip hardening behaviour and undergo compaction before shearing, while the sedimented one is slip weakening and dilates before shearing, leading to larger deformed areas.

The internal frictions values of the four sands were confirmed by the measurements of the Riedels angles at the surface of the model compared to the basement fault $(\alpha)$, which are homogeneous for a given internal friction value (see experimental results section for measurements Fig. S10). 


\section{Basal friction}

To investigate the effect of the basal friction, we used three different basal materials: PVC, Alkor foil $®$ and a sand paper with the same granulometry as Sand 1. Their basal frictions were measured with ring-shear tests (Krantz, 1991). Sands were sifted in a movable ring on the tested basal materials. The ring is laterally displaced by a mass exerting a lateral force. This force and the ring displacement are recorded during the whole experiment. The force needed to move the ring increase regularly before reaching a plateau (Fig. S6), whose value depends on the normal constraint applied on the ring. The linear regression of the tangential force versus normal stress values provides the basal friction value. We obtained a low basal friction for the Sand 1 (CV32) on PVC: $\phi_{\mathrm{b}}=$ $13^{\circ}$, intermediate ones for Sand 1 on Alkor foil ${ }^{\circ}: \phi_{b}=18^{\circ}$, Sand 2 on PVC: $\phi_{b}=23^{\circ}$, Sand 4 on PVC: $\phi_{b}=22^{\circ}$, and a very high one for Sand 1 on sand paper (Fig. S6, Table S2). We were not able to measure precisely the friction of Sand 1 on sand paper because it is most probably higher than its internal friction $\left(\phi_{\mathrm{b}}>\phi_{\text {int }}=43.7^{\circ}\right)$. Instead of using the basal décollement, the shearing zone probably develops in the sand itself. The basal friction in that case is most probably of the order of the sand internal friction. We also measured the basal friction for the sand 3, 4 on PVC. We obtained $\phi_{b}=23^{\circ}$ for Sand 3 on PVC and $\phi_{\mathrm{b}}=22^{\circ}$ for Sand 4 . The measurements with Sand 4 exhibit more variability than others, which could be due to the presence of heterogeneities in the sand mixture link to the large electro-static charge of the C400. 
Sand 2

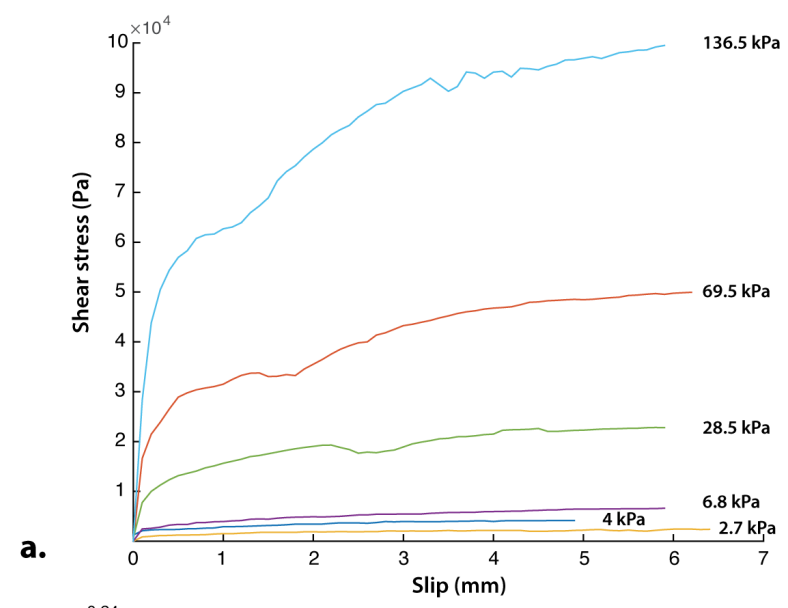

b.
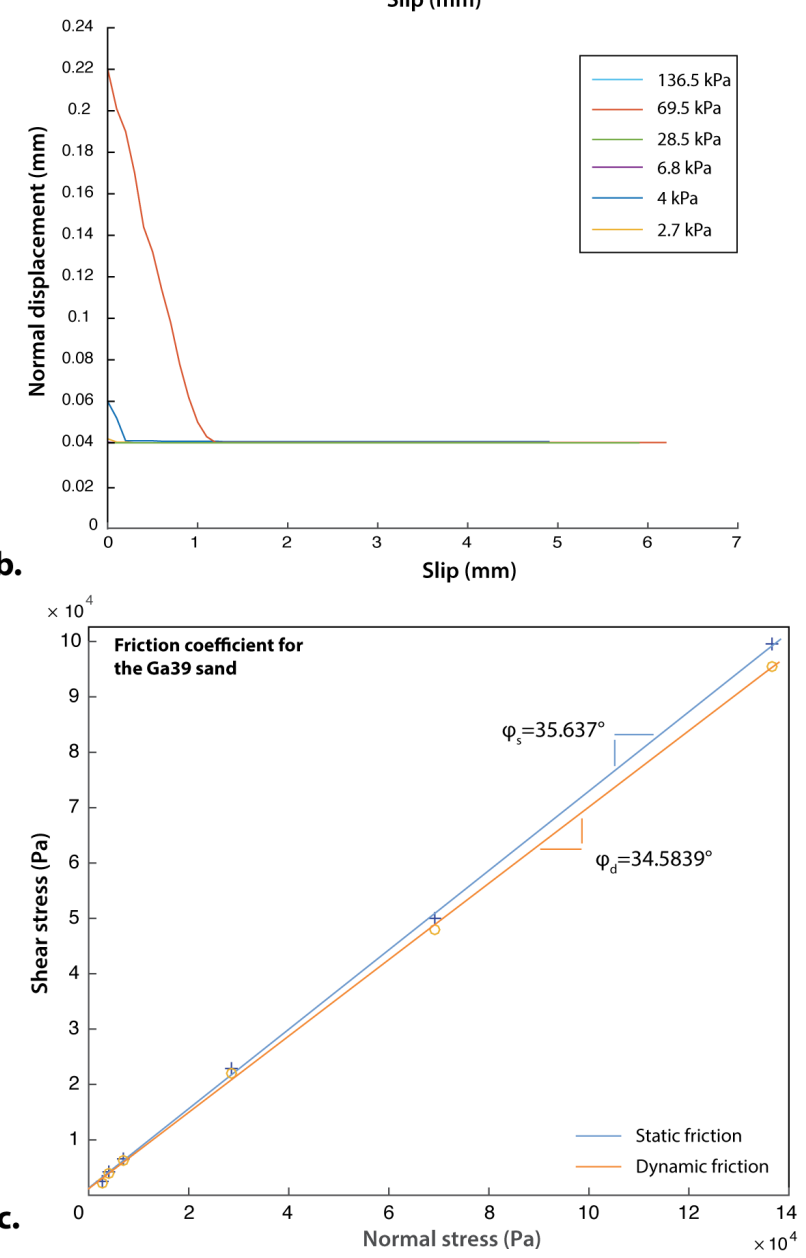

Sand 4
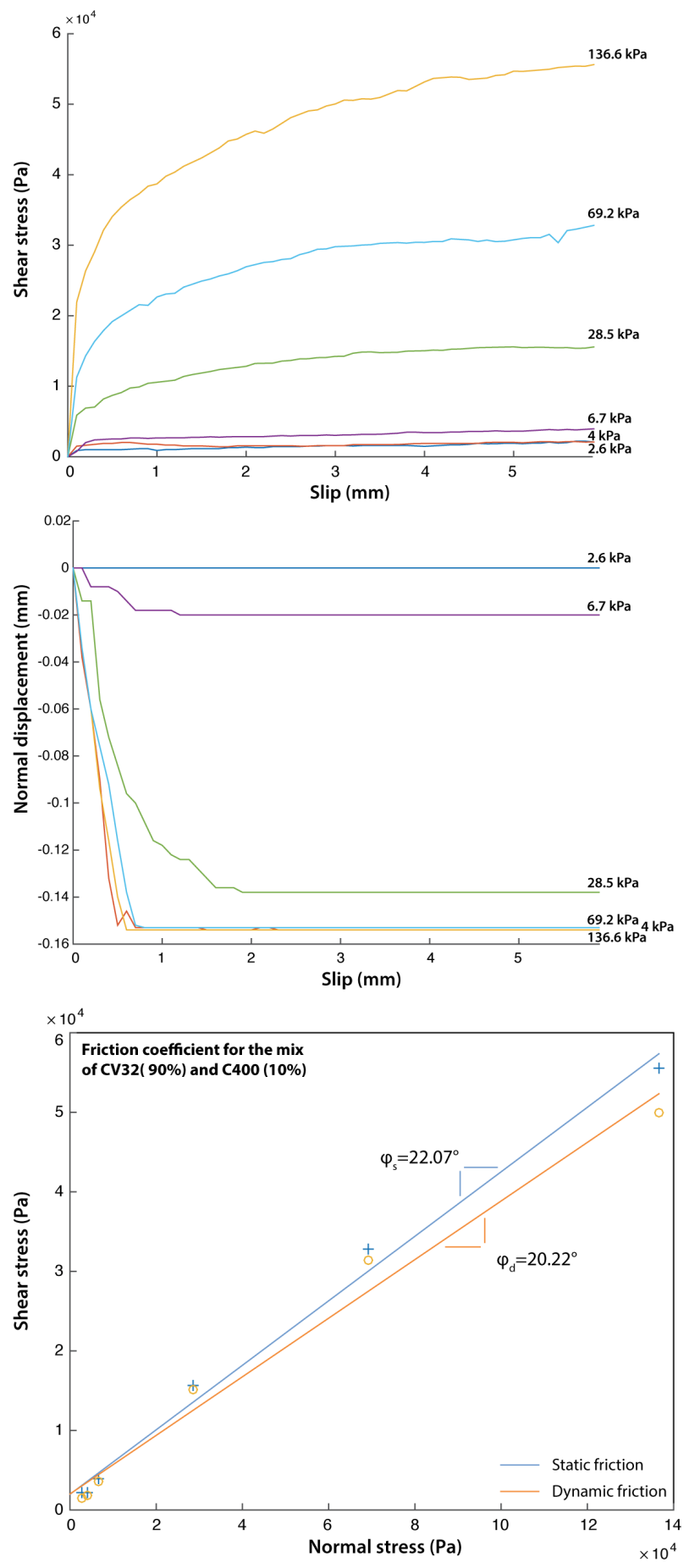

Figure S5: Direct shear tests of Sand 2 (left) and sand 4 (right) in a Casagrande box. a. Shear stress versus displacement curves at various normal stresses. b. Vertical displacement of the top of the sandpack during displacement. c. Linear regression of the peak and stable values of shear versus normal stress, the slopes correspond to the friction values. 

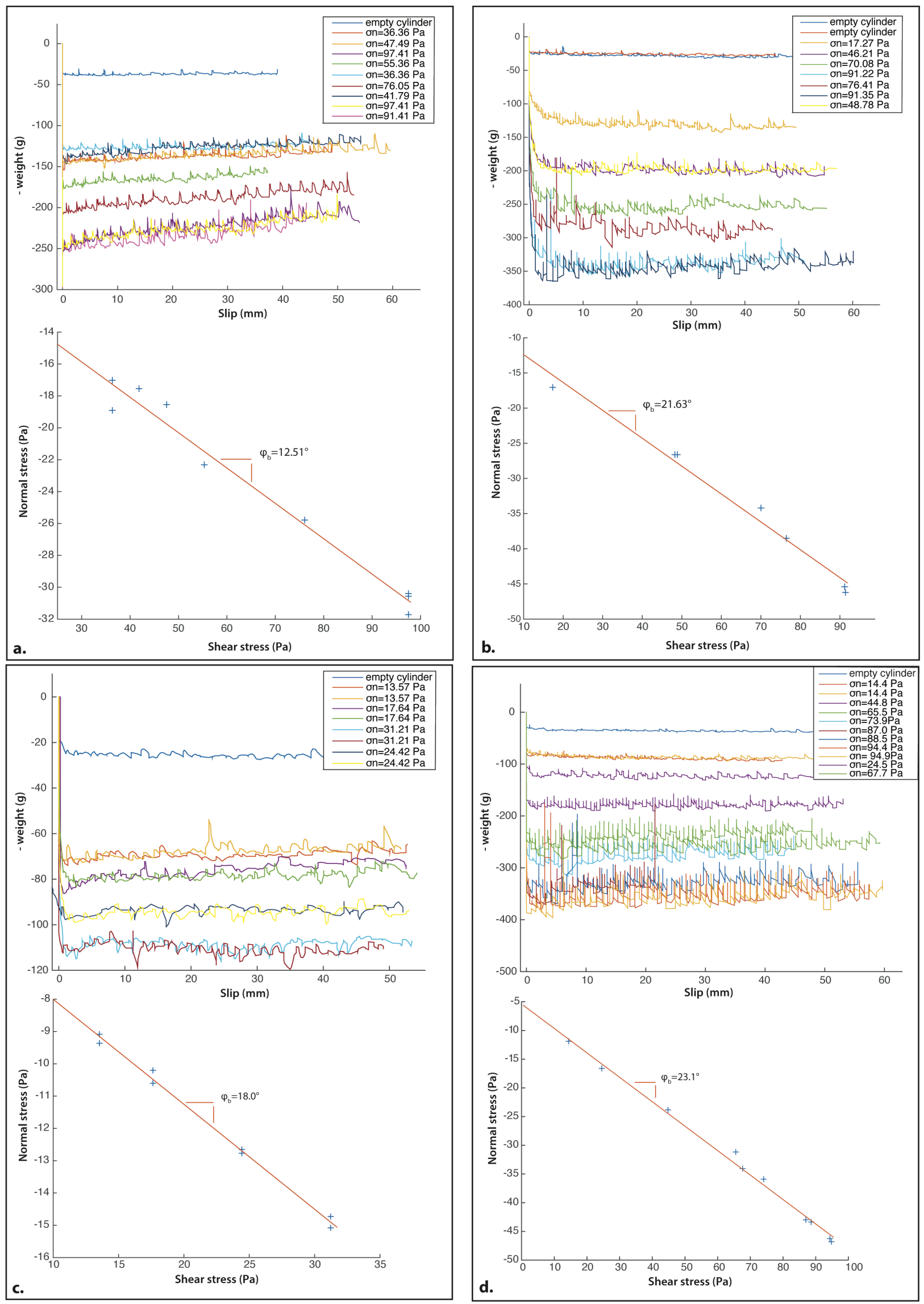

Figure S6: Basal friction ascertainment by shear tests for Sand 1, 3, 4 on PVC and sand 1 
on Alkor-foil@. For each insert, on the top tangential stress during the experiment for different normal stress, at the bottom, linear regression of the stable value of the tangential stress versus normal stress, the slopes give the basal friction values. a. For Sand 1 on PVC. b. For Sand 4 on PVC. c. For Sand 1 on Alkor-foil@. d. For Sand 3 on PVC.

\section{Cohesion}

To test the impact of the cohesion we compared the Sands 3 with a mixture of the CV32 and C400 sands, called Sand 4, both poured. The sand CV32 showed no cohesion $(\mathrm{C}=0$ $\mathrm{Pa})$, whereas the $\mathrm{C} 400$ appeared highly cohesive $(\mathrm{C}=85-120 \mathrm{~Pa})$ due to its fine granulometry. We used a mixture composed of $90 \%$ of CV32 sand and $10 \%$ of C400 sand resulting in a cohesion of about $70 \mathrm{~Pa}$ (Table S2). This cohesion value is relatively high given our experimental set-up. Indeed if we scale our model back to nature, it corresponds to a layer of rocks with a cohesion ranging from 40 to $75 \mathrm{MPa}$, which is higher than the typical range of cohesion considered for the crust, comprised between 5 and $20 \mathrm{MPa}$. The mixture could not be sieved with our device (Maillot, 2013) because of the high electrostatic force of fine sands.

\section{Experiment results:}

The width of the shear zone and the size of Riedel shears are supposed to depend on the physical properties of the granular material (Tchalenko, 1970). We thus used three different sands and three different basement materials to investigate the impact of the internal friction, of the basal friction and of the cohesion. The parameters of the experiments are summarized in table S2.

\begin{tabular}{lccccc}
\hline \multicolumn{1}{c}{ sand } & $\begin{array}{c}\text { internal friction } \\
\boldsymbol{\varphi} \mathbf{i}(\mathbf{d e g})\end{array}$ & coesion C (Pa) & $\begin{array}{c}\text { basal friction } \\
\boldsymbol{\varphi} \mathbf{b}(\mathbf{d e g})\end{array}$ & $\begin{array}{c}\text { number of } \\
\text { experiments }\end{array}$ & $\begin{array}{c}\text { range of } \\
\text { thickness }(\mathbf{c m})\end{array}$ \\
\hline Sand 1 on PVC & 43.7 & 0 & 13 & 24 & $2-2.5-3-3.5-4-5-6$ \\
Sand 1 on alkor foil ${ }^{\otimes}$ & 43.8 & 0 & 18 & 5 & $2-2.5-3-3.5-4$ \\
Sand 1 on sand-paper & 43.9 & 0 & $>43$ & 6 & $2-2.5-3-3.5-4-5$ \\
Sand 2 & 34.5 & 0 & 23 & 6 & $2-2.5-3-3.5-4-5$ \\
Sand 3 & 33.4 & 0 & 13 & 5 & $2-3-3.5-4-5$ \\
Sand 4 & 22.1 & $65-80$ & 20 & 3 & $2-3-4$ \\
\hline
\end{tabular}

Table S2: Experimental parameters. The height of the horizontal sand pack, cohesion, internal and basal frictions vary among experiments.

The data from the laboratory experiment have been uploaded to the repository for physical models run by GFZ Data Services (Lefevre et al., 2020). 


\section{The Inter-Riedel distance:}

\section{Internal friction:}

For the three internal frictions, we observe a similar tendency: the inter-Riedel distance increases with the sand-pack thickness (Fig. 2, S7). The different distributions of S versus $\mathrm{T}$ are well reproduced by linear relations. For Sand $1\left(\phi_{\text {int }}=43.7^{\circ}\right): \mathrm{S}=2.69 \mathrm{~T}-2.59$, $\mathrm{r}^{2}=0.85$, for Sand $2\left(\phi_{\text {int }}=35.6^{\circ}\right): S=1.61 \mathrm{~T}-0.66, \mathrm{r}^{2}=0.93$ and for Sand $3\left(\phi_{\text {int }}=33.4^{\circ}\right): \mathrm{S}=$ $1.43 \mathrm{~T}-0.81, \mathrm{r}^{2}=0.96$.

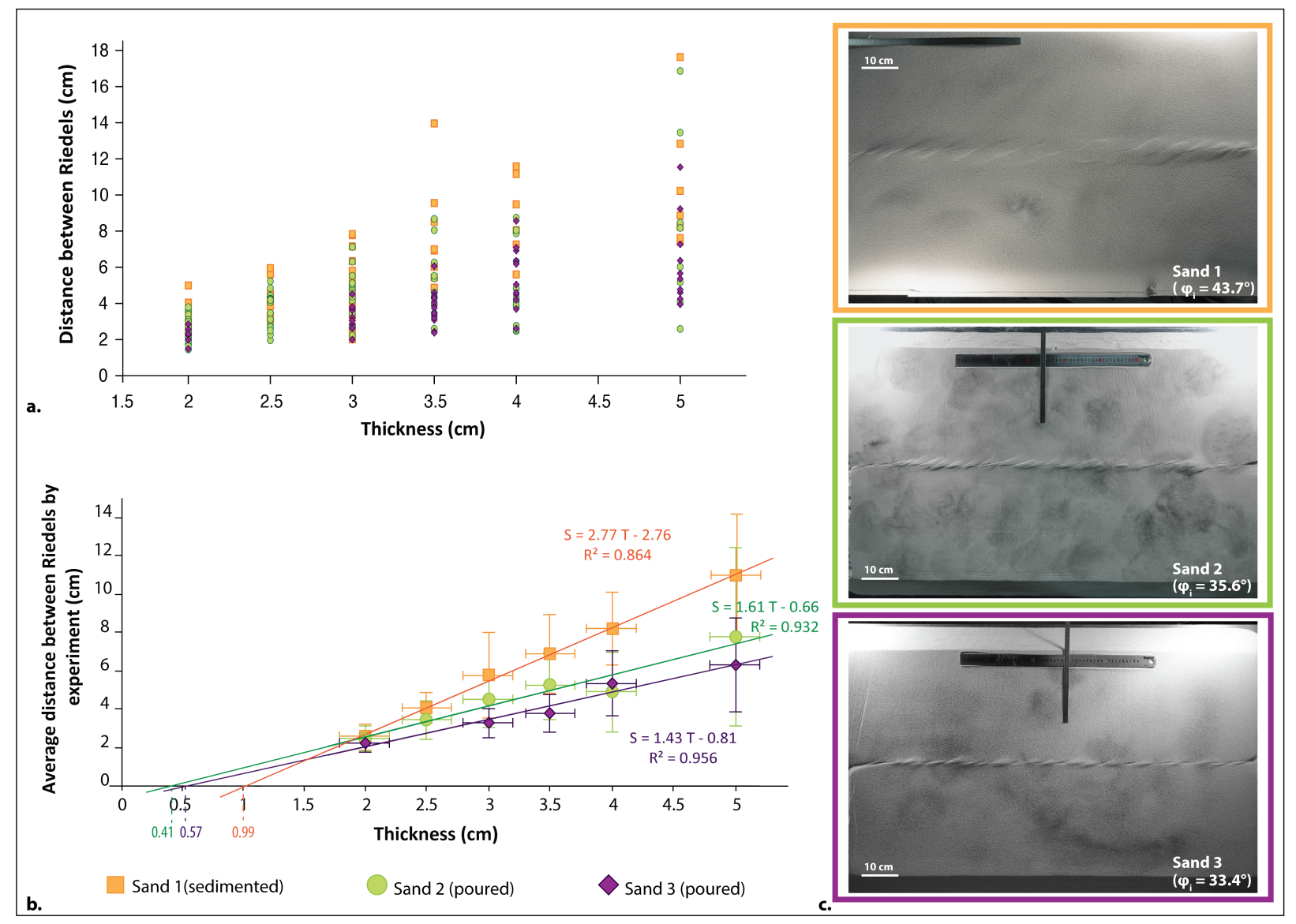

Figure S7: Comparison of the inter-Riedel distance versus the sandpack thickness for three values of the internal friction. a. Measurements of the distance between consecutive Riedel versus the sand-pack thickness. b. Average inter-Riedel distance per experiment versus sandpack thickness. c. Pictures of the top of the sandbox after $\sim 11-$ $12 \mathrm{~mm}$ of displacement for a $4 \mathrm{~cm}$-thick sandpack for each internal friction. 


\section{Basal friction:}

The distribution of the inter-Riedel distance (S) for the three different basal frictions is shown in figure S8. The three sets of measurements are well described by linear regressions. For Sand 1, with sand paper $\left(\varphi_{\mathrm{b}}>43.4^{\circ}\right)$, we obtained $S=3.17 \mathrm{~T}-1.17, \mathrm{r}^{2}=$ 0.91 , with Alkor foil $囚\left(\varphi_{b}=18^{\circ}\right)$, we found $S=2.98 \mathrm{~T}-2.45, \mathrm{r}^{2}=0.95$ and on the PVC $\left(\varphi_{\mathrm{b}}=13^{\circ}\right), \mathrm{S}=2.69 \mathrm{~T}-2.59, \mathrm{r}^{2}=0.85$.

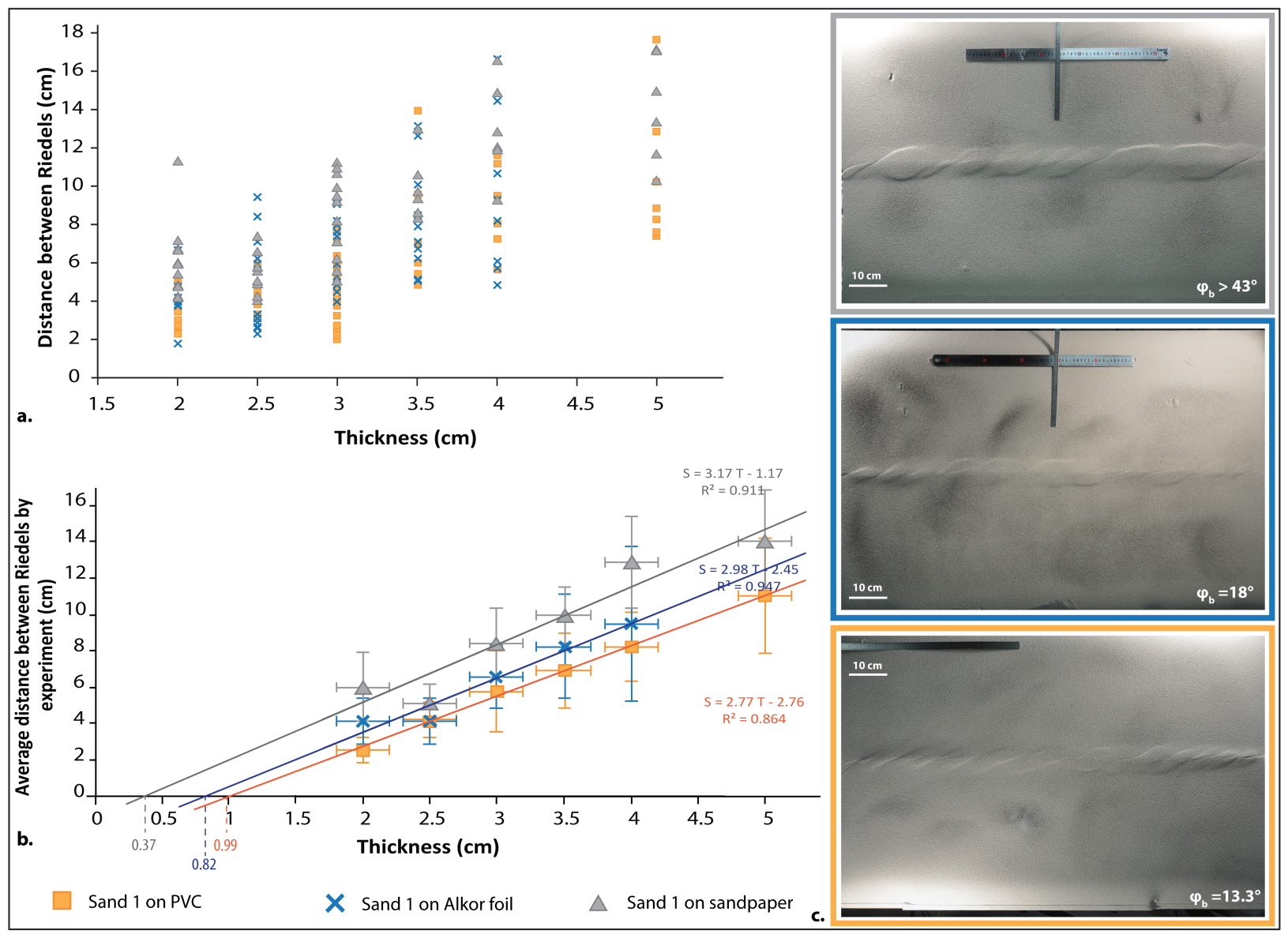

Figure S8: Comparison of the inter-Riedel distance versus the sand-pack thickness for three values of basal friction. a. Measurements of the distance between consecutive Riedel versus the sand-pack thickness. b. Average inter-Riedel distance per experiment versus sand-pack thickness. c. Pictures of the top of the sandbox after $\sim 11-12 \mathrm{~mm}$ of displacement for a $4 \mathrm{~cm}$-thick sandpack for each basal friction. 


\section{Cohesion:}

The structures created with the more cohesive material are larger than the ones obtained with Sand 3 (Fig. 2, S9). The average of S for Sand 4 experiments also increases linearly with T, with the same slope as sand 3 but shifted upwards by $1.5 \mathrm{~cm}$.

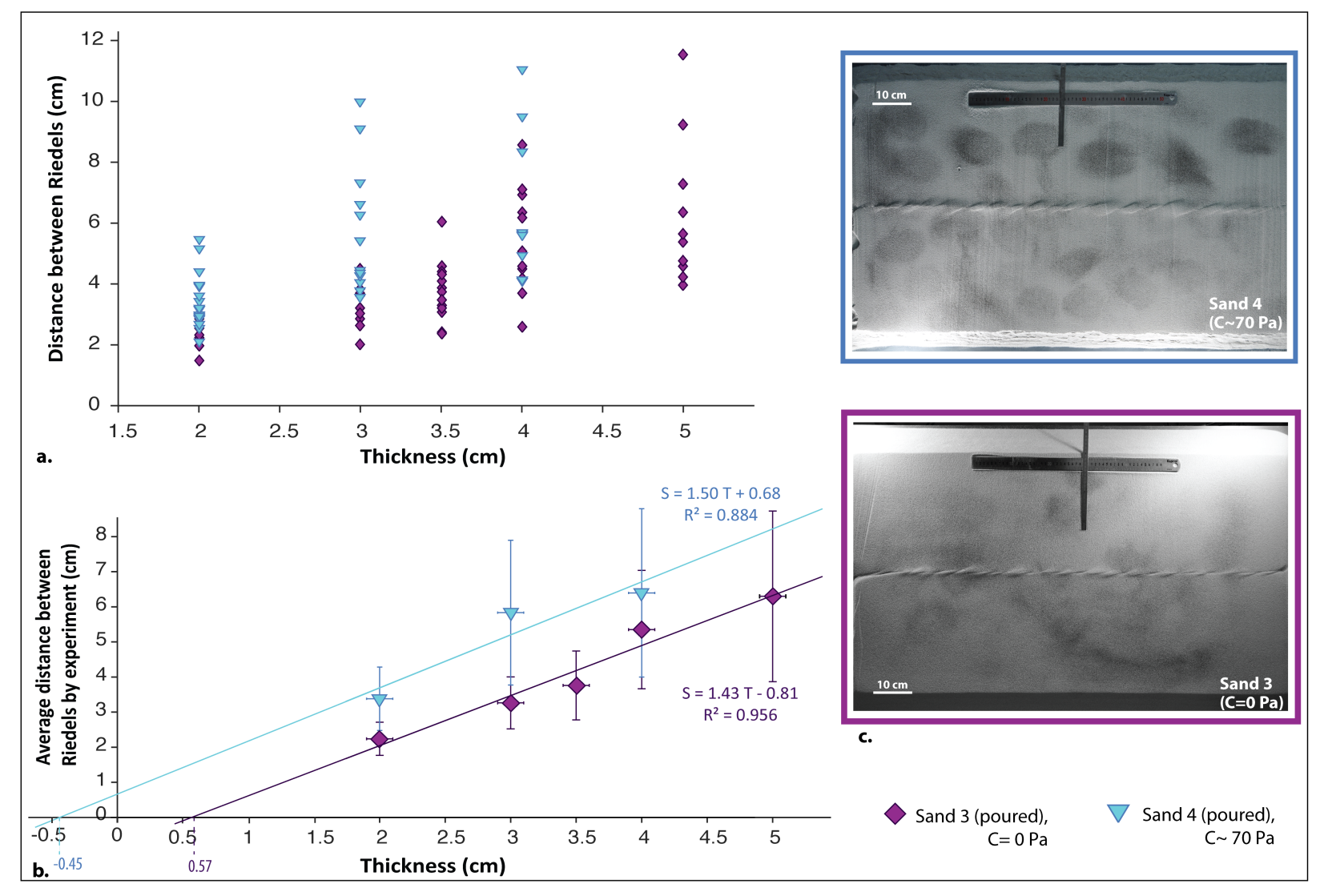

Figure S9: Impact of the cohesion on the strike-slip fault structure. a. Measurements of the distance between consecutive Riedels versus the sandpack thickness for two materials of different cohesion. b. Average inter-Riedel distance per experiment versus sandpack thickness. c. Pictures of the top of the sandbox after $\sim 11-12 \mathrm{~mm}$ of displacement for a $4 \mathrm{~cm}$-thick sandpack for the two values of cohesion.

\section{The Riedel angles:}

We measured the Riedels angles with the basement fault as they are supposed to depend on the internal friction. The angles of the Riedels are homogeneous for each internal friction (Fig. S10). We find average angles corresponding to the theoretical values $\alpha=\varphi_{\text {int }} / 2$.For Sand 1 , the mean value is $25^{\circ} \pm 3.5^{\circ}$, for Sand 2 it is $21^{\circ} \pm 3.5^{\circ}$, and we obtained $18^{\circ} \pm 3.5^{\circ}$ for Sand 3, confirming our ring shear test measurements (Table S2). We can notice that the angles measured for the thicker experiments $(T=5 \mathrm{~cm})$ are in average higher than the expected value, which could be due to edge effects, as we reach the limit thickness allowed by our sandbox. 


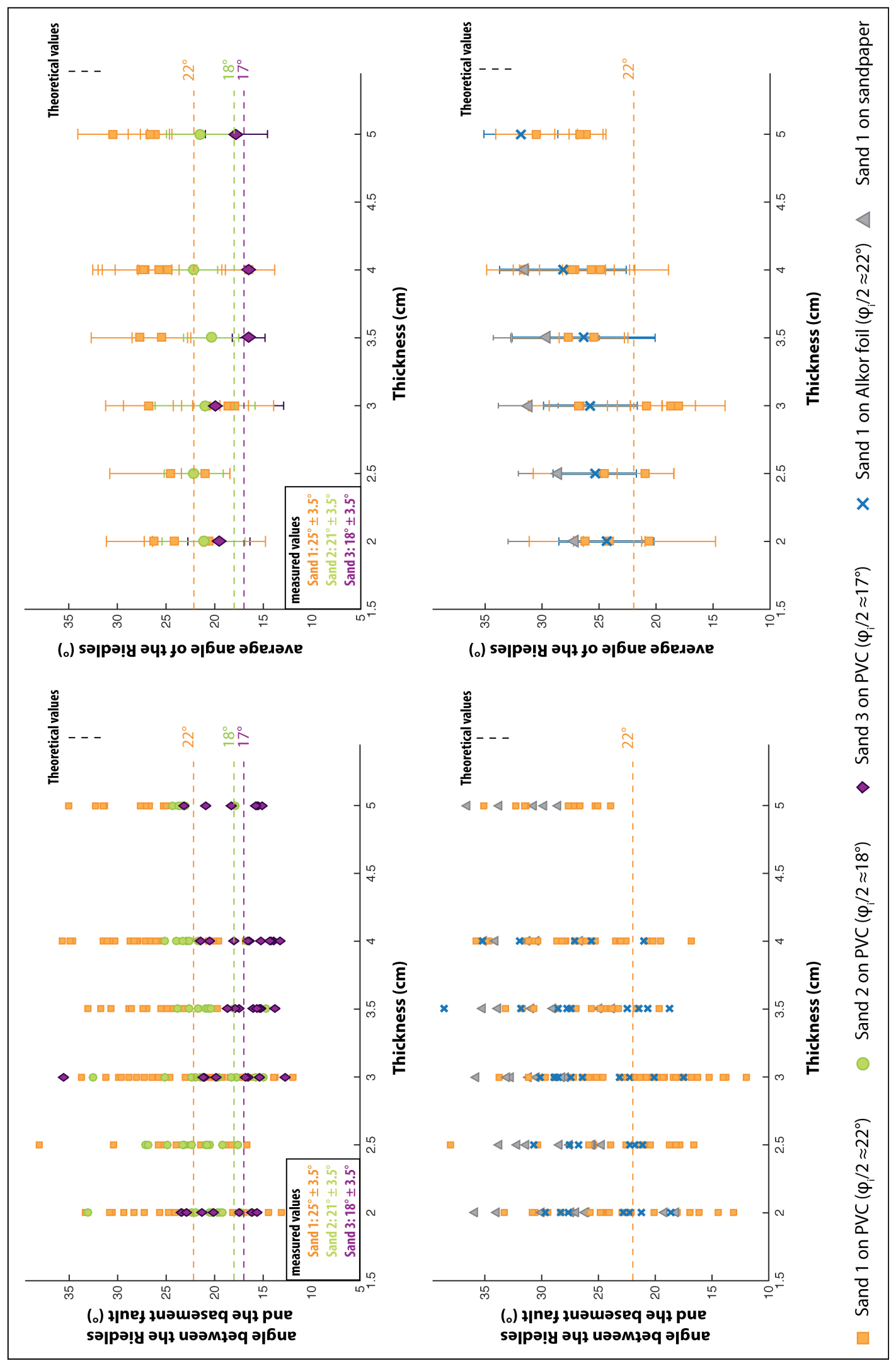

Figure S10: Angle between Riedels at the surface and the basement fault versus sandpack thickness. On the top comparison of the angles distribution for three internal frictions, data (left) and average by experiment (right), at the bottom comparison of the angles distribution for three basal frictions, measurements (left) and average by experiment (right). 


\section{The Riedel lengths:}

We measured the lengths of the Reidels in every experiment, for each set of parameters. The distribution of the lengths of Riedels versus sand-pack thickness follows a linear relation (Fig. S11). For the experiments with different basal frictions the sets of measurements are superimposed and the relations are similar (Fig. S11.b). Thus, the basal friction does not impact the length of Riedels. Nevertheless for the experiments with different internal friction, we identified two tendencies. Sand 1 presents a different behaviour compared to the sands 2 and 3. The slope of the linear regression of $L$ versus $\mathrm{T}$ is stronger than for the other sands, although the internal friction variation is relatively small. Sand 1 is the only sedimented sand. The difference of deposition mode might explain the disparity of the Riedel lengths distributions. Indeed it has been shown that the deposition mode affects the material properties, as the internal friction but also the mechanical behaviour (Maillot, 2013). The sedimentation creates slip weakening sands well conducive to strain localisation, while the poured sands are slip strengthening. In our experiments. Sand 1 dilates before the formation of the shear zones leading to an enlargement of the deformation zone whereas sands 2 and 3, which are strengthening, compacts before shearing (Fig. S5). As the Riedels length is controlled by the width of the deformation zone (Tchalenko, 1970; Atmaoui et al., 2006), it is thus strongly linked to the mechanical behaviour of the sand (Fig. S5).

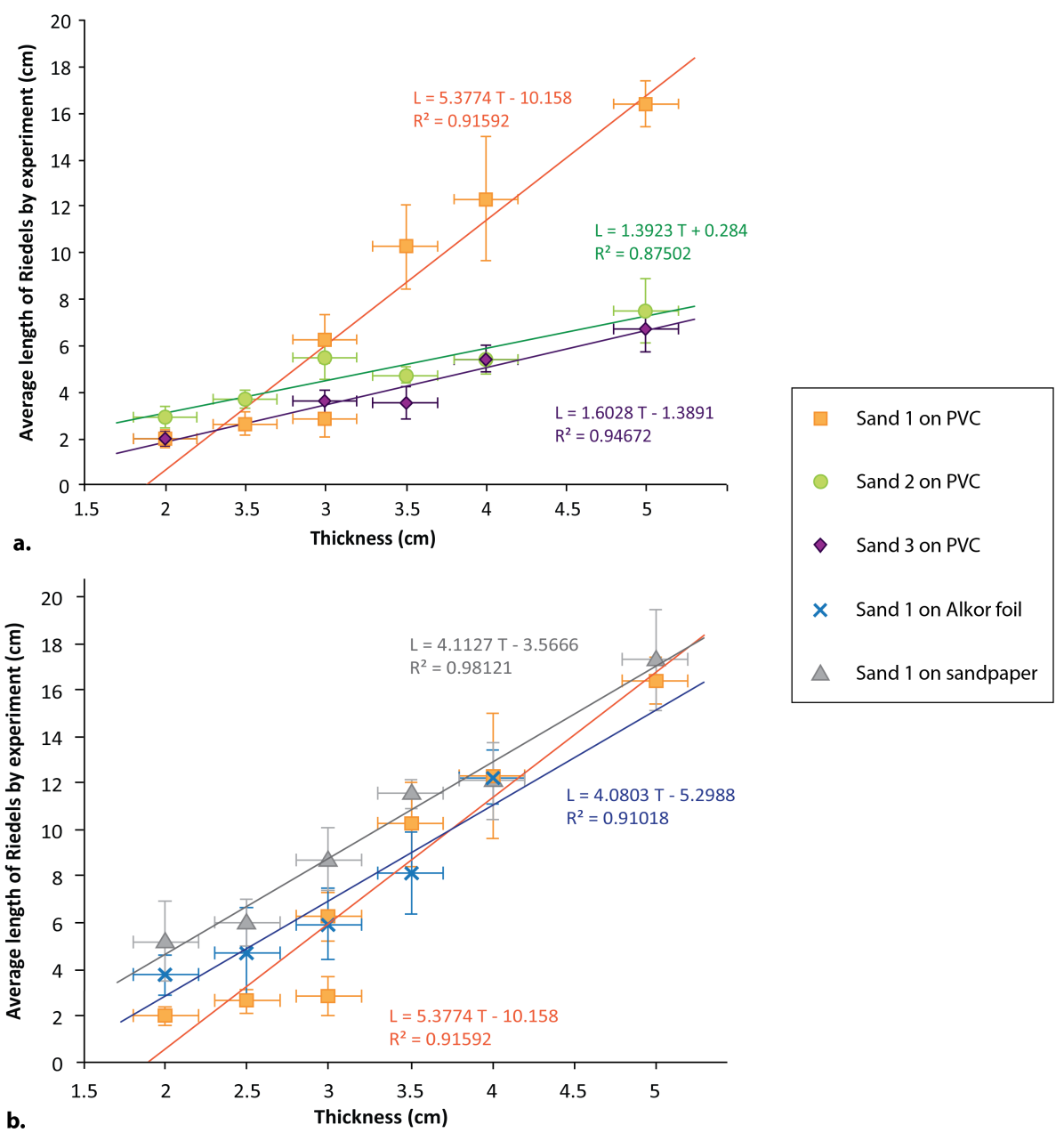

Figure S11:

Average values per experiment of the Riedel length versus sandpack thickness.

a. values for three distinct internal frictions. b. values for three basal frictions. 


\section{Mechanical implications of our results for the Riedel formation:}

We have seen that the inter-Riedel distance is controlled by the thickness of the sandpack, while the material properties have second order effects. The internal friction or possibly the mechanical properties control the scaling factor of the linear relationship between sand thickness (T) and inter-Riedel distance (S). As Riedel shears are formed when shear stress reaches the static friction (Tchalencko, 1970), we do not think that the rate-hardening or weakening behavior of the sands is responsible for the observed variations of structure sizes. Another parameter that changes between the three tested sands in Fig. S7 is the dilatancy, only Sand 1 dilates, as a result of its weakening behavior. Nevertheless, it is not clear whether dilatancy impacts the size of the structures or if the structures control the width of the dilated area. As a consequence, we think that the internal friction is the main parameter responsible for the difference. In addition, the dilatancy observed with Sand 1 does not scale like what we can expect on earth. Indeed, we computed DEMs of the surface of a few experiments performed with Sand 1, for these 4cm-thick experiments we observed a swelling of around 3-4 mm, i.e. a tenth of the experiment thickness. Given the scaling associated to this low cohesion sand, this swelling would be equivalent in nature to a kilometre-scale relief associated to the strike-slip motion, which appears unrealistic. In view of this high dilatancy, this sand might not be an appropriate choice for a crustal analog, that is why we will not consider it in comparison with natural cases.

In our scenarios, the segmentation of strike-slip faults is determined early on, in fact as soon as the Riedels appear. Since they are the first structures to appear, at this point there is no strength contrast in the material, indeed it has been shown by Tchalenko 1970 and Ritter et al. 2018 that the Riedels form when the shear stress reaches the static friction, the latter decreases only once the S shears are formed. Moreover, the Riedels accommodate little slip and are not mature, so the sliding friction does not matter in this case. This is confirmed by the fact that the angle of the Riedels with respect to the basal fault is known to be (internal friction)/2, and in our experiments we measured a value corresponding to (static friction)/2 (see figure S10). This would mean that the segmentation of strike-slip faults is independent of the fault maturity and the effect of the strength contrast on this segmentation is negligible.

The basal friction does not seem to affect the slope of the relation between the interRiedel spacing $(\mathrm{S})$ and the thickness $(\mathrm{T})$, but a change of basal friction leads to a change of intercept. The variations of intercept mainly reflect the variations of the intercept with the $\mathrm{x}$-axis, the latter corresponding to the minimal thickness necessary to develop the 3D-helicoide. We suspect that the value of this threshold is thus linked to the distribution of the different stresses in the cover, which are controlled by the frictional properties of the material. Indeed the rotation is due to the decrease from the base of the model to the surface of the two shear stresses (parallel to the basement-sandpack contact and parallel to the projection of the basement fault). The rate of decrease 
depends on the frictional properties of the model, thus the basal friction has an impact on the shape of the envelope of the deformed area, particularly at depth.

In the experiments the deformation is confined in a central area and tends to localize with the increase of the accumulated slip. At the beginning we observe relatively diffuse deformation, associated to dilatation for the weakening sands, then Riedels appear at the surface. Finally the zone of active deformation narrows when S-shears appear at the surface and coalesce. The diffuse deformation at the surface during the initial stage of deformation already reflects the localization of the upcoming Riedels, suggesting their presence in depth (Fig S12). This highlights that in the sandbox the structures propagate upward and that the deformation is essentially of the "mode III" type, which is partly due to the setup, where we impose a strong kinematic boundary with the localized basal dislocation (e.g. Hatem et al. 2017, Ritter et al. 2018). The presence of a zone of distributed deformation at the base of the model will enlarge the structures (e.g. Schreurs 2003, Hatem et al. 2017), but our set-up does not allow us to test the impact of this parameter. 


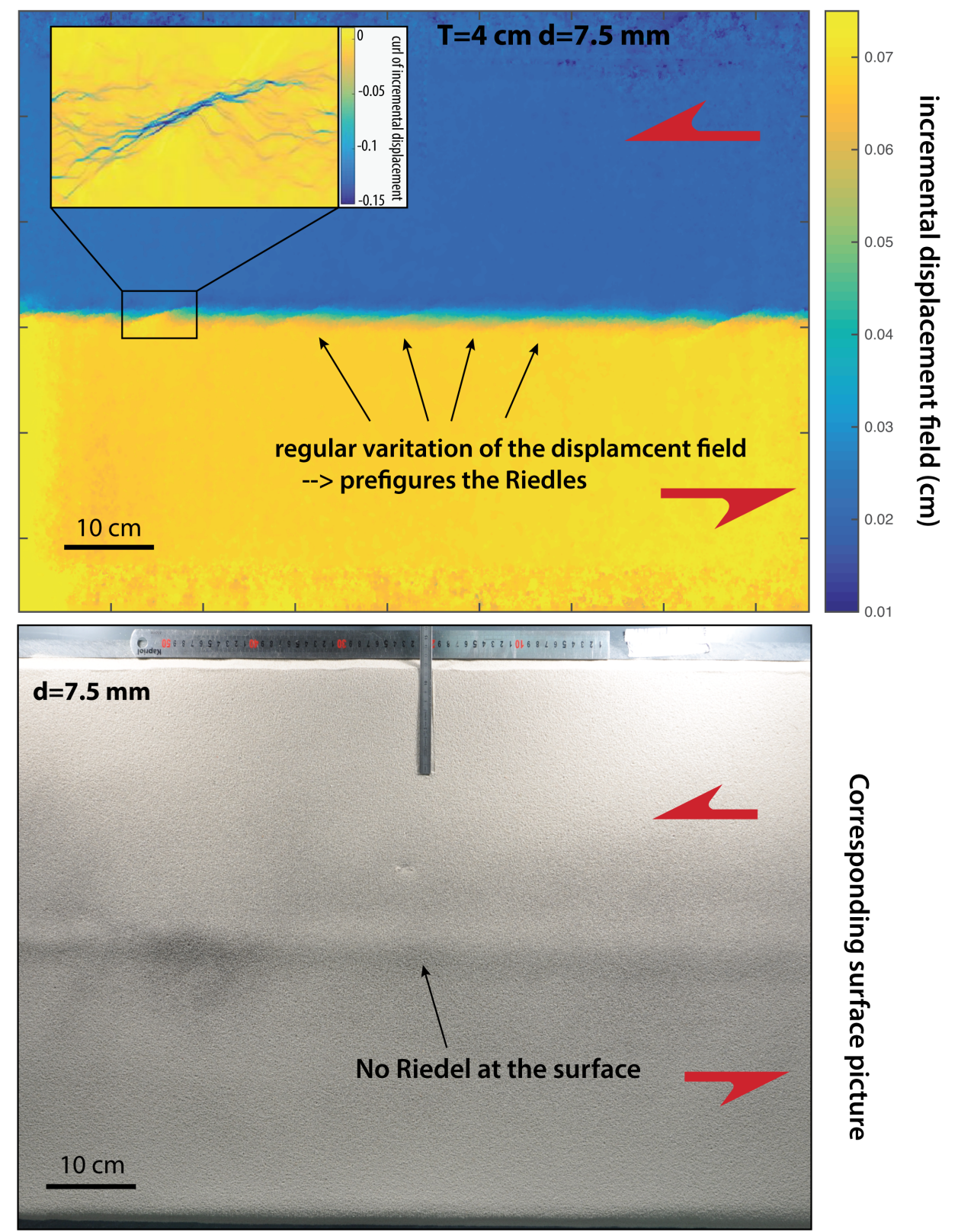

Figure S12: (top) Incremental displacement field obtained from image correlation for a 4-cm-thick experiment, we can observe that the deformation at the sandbox surface exhibit a regular pattern similar to the one of the Riedels, and this before they reach the surface. Indeed the corresponding surface picture (bottom) does not contain any Riedel, we only distinguish the central dilated area.

\section{Seismogenic thickness:}

To compare the inter-Riedels spacing measured in our experiments with the segment length measured on surface co-seismic rupture maps, we need to normalize both datasets. We choose to normalize by the thickness of the brittle frictional layer, i.e. by 
the thickness of the sand-pack for the experiments and the thickness of the seismogenic crust for the fault segments.

The values of the thickness of the seismogenic crust, which is considered to be the depth until which background microseismicity is registered (Scholz 1990), can be difficult to assess depending on the area and subject to large uncertainty. Here we use values from the literature, for a first assessment we did not look at the effect of the uncertainties and used only one value of seismogenic thickness for each earthquake. Most of the values here came from Klinger 2010 and references cited therein (Table S3).

\begin{tabular}{|c|c|c|c|}
\hline earthquake & $\begin{array}{l}\text { proposed thickness of the } \\
\text { seismogenic crust }(\mathrm{km})\end{array}$ & references & $\begin{array}{l}\text { value used for the } \\
\text { normalization }(\mathrm{km})\end{array}$ \\
\hline \multirow[t]{2}{*}{ Hector Mines } & $12.4+/-2$ & Nazareth and Hauksson 2004 & \multirow{2}{*}{12} \\
\hline & $11.9+/-1.1$ & Zuza et al. 2017 & \\
\hline \multirow[t]{2}{*}{ Landers } & $12.4+/-2$ & Nazareth and Hauksson 2004 & \multirow{2}{*}{12} \\
\hline & $12.1+/-1.5$ & Zuza et al. 2017 & \\
\hline Owen valley & $10.6+/-1.4$ & Yang et al. 2020 & 11 \\
\hline \multirow[t]{2}{*}{ Superstition Hills } & $11.4+/-1$ & Nazareth and Hauksson 2004 & \multirow{2}{*}{12} \\
\hline & $15.7+/-1.1$ & Zuza et al. 2017 & \\
\hline Kokoxili & $14.5+/-0.7$ & Zuza et al. 2017 & 15 \\
\hline Gobi Altay & $15-20$ & Bayasgalan et al. 2005 & 17 \\
\hline \multirow[t]{3}{*}{ Haiyuan } & $\approx 16$ & Lassere et al. 2001 & \multirow{3}{*}{16} \\
\hline & $\approx 20$ & Jolivet et al. 2012 & \\
\hline & $14.5+/-0.7$ & Zuza et al. 2017 & \\
\hline \multirow[t]{2}{*}{ Baluchistan } & $15-20$ & Lauer et al. 2018 & \multirow{2}{*}{16} \\
\hline & $10-18$ & Jolivet et al. 2014 & \\
\hline Luzon & $20-25$ & Galgana et al. 2007 & 20 \\
\hline \multirow[t]{2}{*}{ Korizan } & $13.3+/-2.1$ & Zuza et al. 2017 & \multirow{2}{*}{15} \\
\hline & $<20 \mathrm{~km}$ & Engdahl et al. 2006 & \\
\hline \multirow[t]{3}{*}{ Zirkuh } & $15-20$ & Gheitanchi and Raeesi 2004 & \multirow{3}{*}{15} \\
\hline & $13.3+/-2.1$ & Zuza et al. 2017 & \\
\hline & $<20 \mathrm{~km}$ & Engdahl et al. 2006 & \\
\hline
\end{tabular}

Table S3: Values of the seismogenic crust thickness for the different tested earthquakes and their sources. 


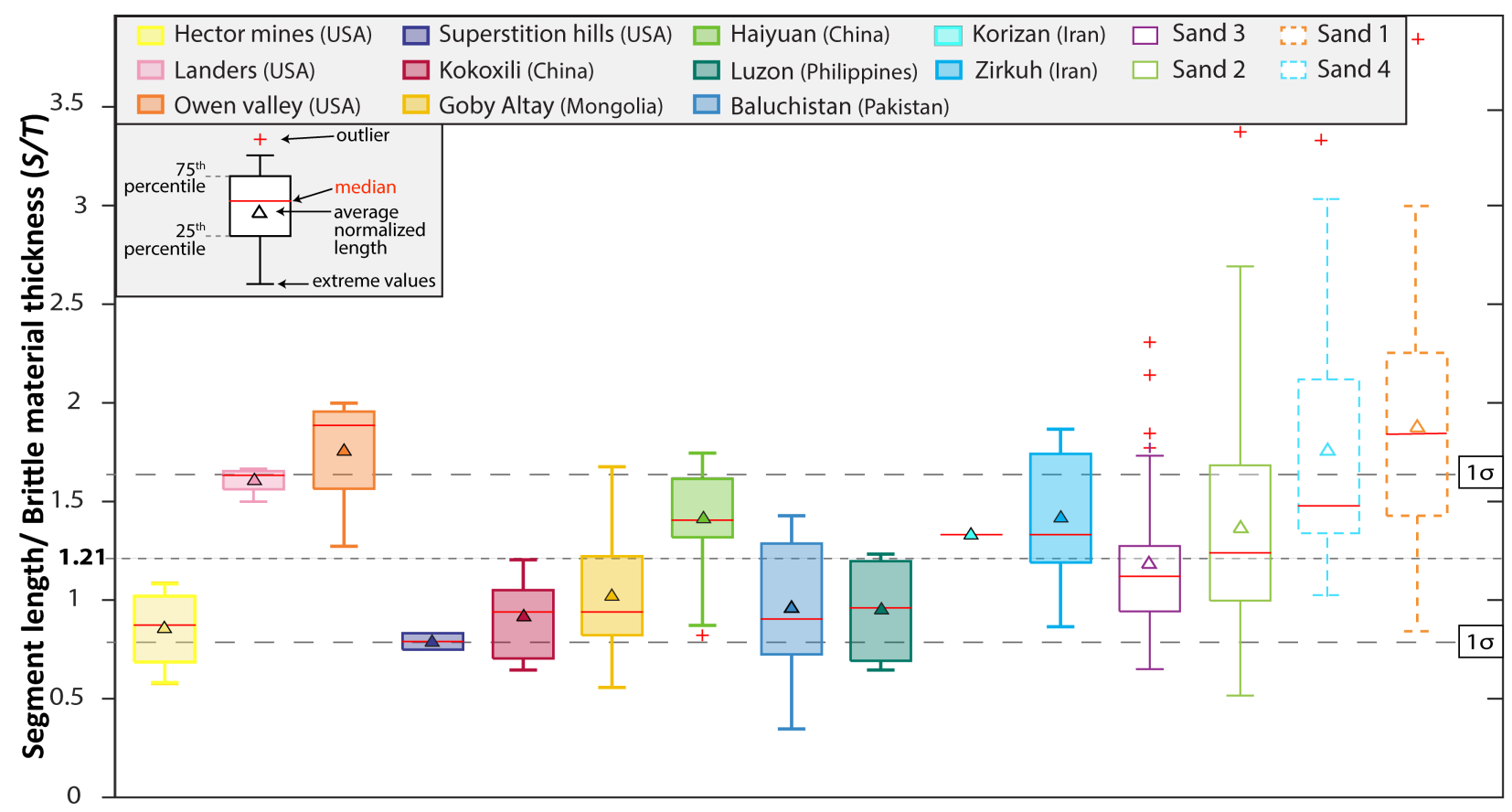

Figure S13: Normalised length of individual fault segments for several continental strike-slip earthquakes (Klinger, 2010, Lauer et al., 2018) and for individual analoguefault segments. The sands 1 and 4 are not used in the calculation of the average ratio and its uncertainty $(\sigma)$. The length is normalized to inferred seismogenic thickness or sand thickness accordingly. Values of seismogenic crust thicknesses are estimated from the literature (see previous section). The Sand 4 presents a high dispersion, probably associated to heterogeneities in the mixing, but its median value agrees with the trend observed in natural cases and sand 2 and 3.

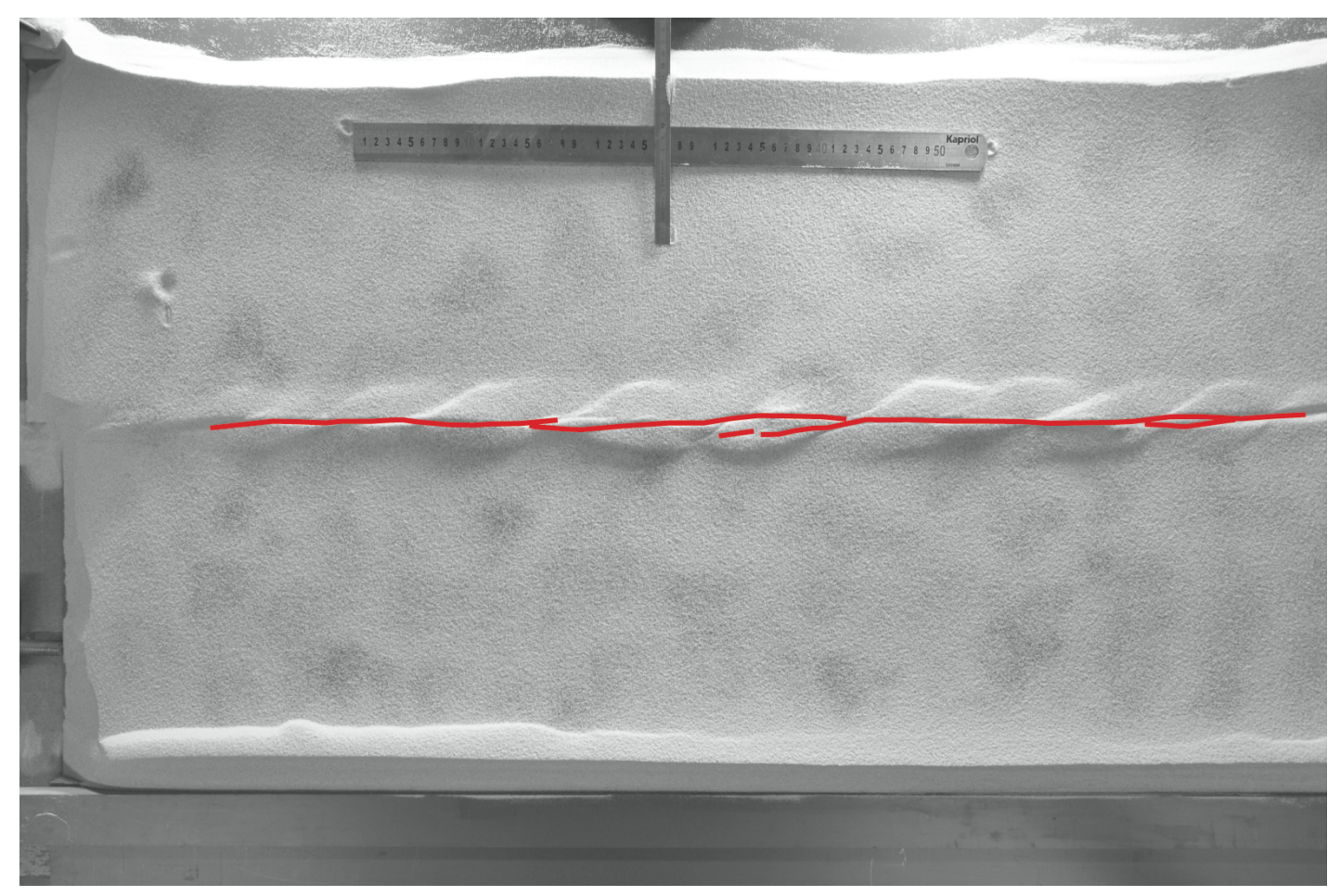

Figure S14: map of the active shears in the experiment, when the P-shears have already linked to form a continuous fault. 


\section{References}

Atmaoui, N., Kukowski, N., Stöckhert, B., and König, D., 2006, Initiation and development of pull-apart basins with Riedel shear mechanism: insights from scaled clay experiments: International Journal of Earth Sciences, v. 95, no. 2, p. 225-238, doi: 10.1007/s00531-005-0030-1.

Bayasgalan, A., Jackson, J., \& McKenzie, D., 2005, Lithosphere rheology and active tectonics in Mongolia: relations between earthquake source parameters, gravity and GPS measurements: Geophysical Journal International, v. 163, no. 3, p. 1151-1179.

Cubas, N., Maillot, B., and Barnes, C., 2010, Statistical analysis of an experimental compressional sand wedge: Journal of Structural Geology, v. 32, no. 6, p. 818-831, doi: 10.1016/j.jsg.2010.05.010.

Engdahl, E. R., Jackson, J. A., Myers, S. C., Bergman, E. A., \& Priestley, K., 2006, Relocation and assessment of seismicity in the Iran region: Geophysical Journal International, v. 167 , no. 2, p. 761-778.

Galgana, G., Hamburger, M., McCaffrey, R., Corpuz, E., \& Chen, Q., 2007, Analysis of crustal deformation in Luzon, Philippines using geodetic observations and earthquake focal mechanisms: Tectonophysics, v. 432, no. 1-4, p. 63-87.

Gheitanchi, M.-R., and Raeesi, M., 2004, Analysis of the 1997 Zirkuh (Ghean-Birjand) aftershock sequence in east-central Iran: Acta Seismologica Sinica, v. 17, no. 1, p. 3846, doi: 10.1007/BF03191393.

Hatem, A.E., Cooke, M.L., Toeneboehn, K., 2017, Strain localization and evolving kinematic efficiency of initiating strike-slip faults within wet kaolin experiments: Journal of Structural Geology, v. 101, p. 96-108, doi: 10.1016/j.jsg.2017.06.011.

Jolivet, R., Lasserre, C., Doin, M.P., Guillaso, S., Peltzer, G., Dailu, R., Sun, J., Shen, Z.K., and $\mathrm{Xu}, \mathrm{X} ., 2012$, Shallow creep on the Haiyuan Fault (Gansu, China) revealed by SAR Interferometry: Journal of Geophysical Research, v. 117, no. B6, p. 1-18, doi: 10.1029/2011JB008732.

Jolivet, R., Duputel, Z., Riel, B., Simons, M., Rivera, L., Minson, S. E., ... \& Fielding, E. J., 2014, The 2013 M w 7.7 Balochistan earthquake: Seismic potential of an accretionary wedge: Bulletin of the Seismological Society of America, v. 104, no. 2, p. 1020-1030.

Klinkmüller, M., Schreurs, G., Rosenau, M., and Kemnitz, H., 2016, Properties of granular analogue model materials: A community wide survey: Tectonophysics, p. 1-16, doi: 10.1016/j.tecto.2016.01.017.

Klinger, Y., 2010, Relation between continental strike-slip earthquake segmentation and thickness of the crust: Journal of Geophysical Research, v. 115, no. B7, p. 1355-19, doi: $10.1029 / 2009 J B 006550$.

Krantz, R.W., 1991, Measurements of friction coefficients and cohesion for faulting and fault reactivation in laboratory models using sand and sand mixtures: 
Tectonophysics, v. 188, no. 1-2, p. 203-207, doi: 10.1016/0040-1951(91)90323-k.

Lasserre, C., Bukchin, B., Bernard, P., Tapponnier, P., Gaudemer, Y., Mostinsky, A., and Dailu, R., 2001, Source parameters and tectonic origin of the 1996 June 1 Tianzhu $(\mathrm{Mw}=5.2)$ and 1995 July 21 Yongden $(\mathrm{Mw}=5.6)$ earthquakes near the Haiyuan fault (Gansu, China): Geophysical Journal International, v. 144, no. 1, p. 206-220, doi: 10.1046/j.1365-246x.2001.00313.x.

Lauer, B., Grandin, R., Klinger, Y., Vallage, A., Jolivet, R., and Delorme, A., 2018, Absence of shallow slip deficit during the Balochistan earthquake (2013, Mw 7.7, Pakistan): insights from SAR and optical-based coseismic slip model: AGU Fall Meeting.

Lefevre, M., Souloumiac, P., Cubas, N., Klinger, Y., (2020) Supplement to "Experimental evidence for crustal control over seismic fault segmentation". GFZ data Services.

Maillot, B., 2013, A sedimentation device to produce uniform sand packs: Tectonophysics, v. 593, no. C, p. 85-94, doi: 10.1016/j.tecto.2013.02.028.

Nazareth, J.J., and Hauksson, E., 2004, The Seismogenic Thickness of the Southern California Crust: Bulletin of the Seismological Society of America, v. 94, no. 3, p. 940960, doi: 10.1785/0120020129.

Panien, M., Schreurs, G., and Pfiffner, A., 2006, Mechanical behaviour of granular materials used in analogue modelling: insights from grain characterisation, ringshear tests and analogue experiments: Journal of Structural Geology, v. 28, no. 9, p. 1710-1724, doi: 10.1016/j.jsg.2006.05.004.

Ritter, M. C., Rosenau, M., \& Oncken, O., 2018, Growing faults in the lab: Insights into the scale dependence of the fault zone evolution process : Tectonics, v. 37, no. 1, p. 140153, doi : 10.1016/j.tecto.2017.11.018.

Rosu, A.-M., Pierrot-Deseilligny, M., Delorme, A., Binet, R., and Klinger, Y., 2015, Measurement of ground displacement from optical satellite image correlation using the free open-source software MicMac: ISPRS Journal of Photogrammetry and Remote Sensing, v. 100, no. C, p. 48-59, doi: 10.1016/j.isprsjprs.2014.03.002.

Scholz, C., 1990, The Mechanics of Earthquakes and Faulting: Cambridge Univ. Press, New York.

Schreurs, G., Hänni, R., Panien, M., \& Vock, P., 2003, Analysis of analogue models by helical X-ray computed tomography: Geological Society, London, Special Publications, v. 215, no. 1, p. 213-223.

Souloumiac, P., Maillot, B., and Leroy, Y.M., 2012, Bias due to side wall friction in sand box experiments: Journal of Structural Geology, v. 35, no. C, p. 90-101, doi: 10.1016/j.jsg.2011.11.002.

Tchalenko, J.S., 1970, Similarities between shear zones of different magnitudes: Geological Society of America Bulletin. 
Yang, H., Moresi, L. N., \& Quigley, M., 2020, Fault spacing in continental strike-slip shear zones : Earth and Planetary Science Letters, v. 530, doi : 10.1016/j.epsl.2019.115906.

Zuza, A.V., Yin, A., Lin, J., Sun, M., 2017, Spacing and strength of active continental strikeslip faults: Earth and Planetary Science Letters, v. 457, p. 49-62, doi: 10.1016/j.epsl.2016.09.041. 